\title{
Serum Low Density Lipoprotein of Alcoholic Patients Is Chemically Modified In Vivo and Induces Apolipoprotein E Synthesis by Macrophages
}

\author{
Renee C. Lin, ${ }^{\star * 5}$ Jiannong Dai, * Lawrence Lumeng, ${ }^{*}$ *5 and Mei-yu Zhang* \\ Departments of ${ }^{*}$ Medicine and ${ }^{\ddagger}$ Biochemistry/Molecular Biology, Indiana University School of Medicine, Indianapolis, Indiana 46202; \\ and the ${ }^{8}$ Veterans Affairs Medical Center, Indianapolis, Indiana 46202
}

\begin{abstract}
This work was carried out to investigate the effect of alcohol drinking on serum LDL. Agarose gel electrophoresis showed that LDL samples from alcoholic patients without serious liver disease were more negatively charged and moved faster toward the cathode than LDL from nondrinking control subjects. Rabbit antibodies raised by using keyhole limpet hemocyanin modified in vitro by 4-hydroxynonenal or by acetaldehyde as immunogens reacted more strongly with patients' LDL than with control LDL, indicating the presence of oxidatively modified epitopes and acetaldehyde adducts in alcoholic patients' LDL. LDL of alcoholic patients has decreased vitamin $\mathbf{E}$ contents. The electromobility of LDL decreased after abstinence from alcohol and returned to normal in 2 wk, but this was not accompanied by a significant increase in its vitamin $E$ contents. When incubated with mouse peritoneal macrophages, patients' LDL induced apolipoprotein $E$ secretion by threefold over control LDL with a concomitant increase in cellular cholesterol. Our results thus demonstrate that LDL of alcoholic patients has lower vitamin $\mathbf{E}$ content, is chemically modified in vivo, and exhibits altered biological function. These changes in heavy alcoholic drinkers may render LDL more atherogenic and thereby may counter the antiatherosclerosis efiects of moderate alcohol consumption. (J. Clin. Invest. 1995. 95:19791986.) Key words: alcohol - vitamin $\mathbf{E} \cdot$ electromobility • cholesterol - cardiovascular disease
\end{abstract}

\section{Introduction}

Epidemiological studies in humans have repeatedly demonstrated a correlation of lower incidence of atherosclerotic cardiovascular disease with moderate alcohol intake $(1,2)$. Many investigations have shown that moderate alcohol drinkers have higher levels of serum high density lipoproteins (HDL) (3-5) and have attributed the lower incidence of atherosclerosis in moderate alcohol consumption to higher serum $\operatorname{HDL}(6,7)$. Although alcohol consumption in moderate amounts is negatively correlated to cardiovascular disease, several studies have consistently found a U-shaped trend showing an increased cardiovascular disease mortality with heavy alcohol drinking and alcohol abuse $(1,8-10)$. Why moderate alcohol consumption

Address correspondence to Renee C. Lin, PhD, Research (151), Veterans Affairs Medical Center, $1481 \mathrm{~W}$. 10th Street, Indianapolis, IN 46202. Phone: 317-635-7401x2528; FAX: 317-269-6370.

Received for publication 22 August 1994 and in revised form 30 November 1994.

The Journal of Clinical Investigation, Inc.

Volume 95, May 1995, 1979-1986 protects against atherosclerotic cardiovascular disease whereas heavy drinking may have the opposite effect remains unclear.

While a positive correlation between coronary artery disease and serum levels of low density lipoproteins (LDL) is well recognized $(11,12)$, it has been suggested recently that oxidatively modified LDL rather than native unmodified LDL is responsible for atherogenesis (13). Native LDL is taken up by the liver and extrahepatic tissues via apo B,E-dependent LDL receptors (14), but the amount of cholesterol accumulated in cells is limited because LDL receptors are downregulated by the intracellular content of cholesterol (14). On the other hand, acetylated LDL (Ac-LDL) ${ }^{1}$ and oxidatively modified LDL (Ox-LDL) are taken up by macrophages via scavenger and additional Ox-LDL specific receptors that are not downregulated by high intracellular cholesterol contents (15-18). When incubated with modified LDL, macrophages become loaded with a large amount of cholesterol esters and resemble foam cells found in atherosclerotic plaques of arterial intima (19). The hypothesis that Ox-LDL may be involved in the pathogenesis of atherosclerosis gains support because oxidatively modified LDL has been detected in atherosclerotic lesions in humans and in rabbits by histoimmunological methods (20). Using a polyclonal antibody that could recognize acetaldehyde-modified epitope (s), Wehr et al. (21) reported recently the presence of acetaldehyde adducts in VLDL and LDL of alcoholic patients by enzyme-linked immunosorbent assay.

LDL is a large molecule. As LDL is modified chemically in vitro, many physical changes ensue including an alteration in electromobility (22). The work reported here was undertaken to investigate whether LDL of alcoholic patients is chemically modified in vivo by measuring its electromobility in agarose gel. Because we have shown previously that Ox-LDL and enzymatically modified LDL, similar to Ac-LDL, can stimulate synthesis and secretion of apo E by peritoneal macrophages (23), the present work also compared the effects of LDL from alcoholic patients and nondrinking controls on apo E secretion and cellular cholesterol accumulation by macrophages.

\section{Methods}

Chemicals. All chemicals purchased from commercial sources were of reagent grades. DME medium was purchased from GIBCO-BRL (Gaithersburg, MD). Fetal calf serum (FCS) was purchased from Sigma Chemical Co. (St. Louis, MO). Each lot was tested for its effectiveness in maintaining good macrophage monolayers before use. 4-hydroxy-2nonenal (HNE) was a generous gift from Professor Hermann Esterbauer (University of Graz, Graz, Austria).

1. Abbreviations used in this paper: AA, acetaldehyde adduct; AcLDL, acetylated LDL; AST, serum aspartate aminotransferase; HNE, 4-hydroxy-2-nonenal; KLH, keyhole limpet hemocyanin; Ox-LDL, oxidatively modified LDL; RT, room temperature. 
Patients and sample preparations. Blood samples were obtained from alcoholic patients admitted to Fairbanks Hospital (an alcoholism rehabilitation hospital), Indianapolis, IN, for detoxification. Ages of patients ranged from 24 to $76 \mathrm{yr}(41 \pm 12 \mathrm{yr})$. These patients all had a long history of alcohol abuse ( $>5 \mathrm{yr}$ ) and reported daily alcohol consumption of no less than $100 \mathrm{~g}$. All of them had been drinking up to within at least $2 \mathrm{~d}$ before admission. Laboratory tests showed $42 \%$ of them had elevated serum aspartate aminotransferase (AST) and 30\% of them had elevated serum alanine aminotransferase, but none showed physical evidence of decompensated liver disease such as low serum albumin $(<3.5 \mathrm{mg} / \mathrm{dl})$, jaundice, ascites, edema, hypersplenism, and hepatic encephalopathy. Control subjects were volunteers recruited from employees of Indiana University and VA Medical Centers. They were either teetotalers or people who consumed only small amounts of alcohol infrequently (no more than one beer a week) and were referred to as nondrinkers in this paper. Analysis of data indicated no gender difference in parameters reported here (see Results), therefore results were not segregated into male and female groups. This project was approved by the Indiana University - Purdue University at Indianapolis Institutional Review Board and by the Administration of Fairbanks Hospital. Informed consents were signed by both control subjects and patients. Venous blood was drawn with heparin as the anticoagulant and immediately placed in ice for no more than $2 \mathrm{~h}$. Erythrocytes and buffy coats were removed by centrifugation at $1,000 \mathrm{~g}$ for $15 \mathrm{~min}$ at $4^{\circ} \mathrm{C}$. Blood samples were also obtained from some alcoholic patients after they had stayed in the alcoholism rehabilitation hospital and abstained from alcohol for 1-2 wk. During hospitalization, patients were given a regular diet and they routinely received daily multiple vitamin supplements including folic acid, thiamine, and vitamin E (30 IU). Freshly prepared plasma samples were heated at $56^{\circ} \mathrm{C}$ for $30 \mathrm{~min}$ to inactivate lecithin/ cholesterol acyltransferase activity. LDL $(1.006<d<1.063)$ was isolated by successive gradient ultracentrifugation with potassium bromide (24) and lipoprotein fractions collected by using a tube slicer (Beckman Instruments, Palo Alto, CA). LDL was dialyzed against 0.15 $\mathrm{M} \mathrm{NaCl}$ containing $1 \mathrm{mM}$ EDTA, pH 7.4, for $48 \mathrm{~h}$ with at least three changes of the buffer. Lipoprotein samples were stored at $4^{\circ} \mathrm{C}$ and used for experiments within 2-3 wk. An aliquot of each LDL sample was saved and frozen at $-20^{\circ} \mathrm{C}$ for the determination of lipids (cholesterol, triglycerides, and phospholipids) within 3 mo.

Measurement of electromobility. Electrophoretic mobilities of LDL preparations were compared by electrophoresis using Ciba Corning Electrophoresis System ${ }^{\mathrm{TM}}$ (Ciba Corning, Medfield, MA) and precasted agarose gel in sodium barbital buffer, pH 8.6 (purchased from Fisher Scientific Co., Cincinnati, OH). Unmodified keyhole limpet hemocyanin was included in each gel as reference. The relative mobility $\left(R_{\mathrm{f}}\right)$ was calculated by setting the $R_{\mathrm{f}}$ of keyhole limpet hemocyanin as 1.0 .

Preparation of antibodies. Antibody that recognized protein-acetaldehyde adduct (AA) was raised using keyhole limpet hemocyanin (KLH) incubated with freshly distilled acetaldehyde $(250 \mathrm{mM})$ and sodium cyanoborohydride as the immunogen (25). To raise antibody that recognized oxidatively modified proteins, $\mathrm{KLH}$ was conjugated to HNE using the method described by Palinski et al. (26). KLH-AA and KLH-HNE were injected into rabbits as immunogens to raise their respective antibodies. IgG fraction was purified from rabbit serum by using a protein A column (Bio-Rad Laboratories, Richmond, CA). Characterization of the anti-KLH-AA antibody has been reported previously (25). We have shown that the antibody reacted with acetaldehyde-modified BSA, myoglobin, and hemoglobin, but not with any of these unmodified proteins (25). When tested by Ouchterlony double immunodiffusion, the anti-HNE-KLH antibody was found to react with 4-HNE-modified BSA and did not recognize unmodified BSA (not shown).

Enzyme-linked immunosorbent assay (ELISA) method. Reactivity between LDL samples and anti-KLH-AA and anti-KLH-HNE IgGs was determined by ELISA method (27). Briefly, diluted LDL ( $1 \mu \mathrm{g} /$ $100 \mu \mathrm{l}$ ) in phosphate-buffered saline (PBS), $\mathrm{pH} 7.4$, was added to 96well ELISA plates and incubated at room temperature (RT) for $2 \mathrm{~h}$. Samples were aspirated and wells were washed with PBS containing
0.05\% Tween-20 (PBST). After the plates were blocked with 1\% BSA, the first antibody (anti-KLH-HNE, anti-KLH-AA, or unimmunized rabbit IgG, $10 \mu \mathrm{g} / \mathrm{ml}$ ) in PBST was added to wells and incubated at RT for $2 \mathrm{~h}$. Plates were washed. Goat anti-rabbit serum IgG conjugated with alkaline phosphatase (Sigma Chemical Co.) was added. After $1 \mathrm{~h}$ of incubation, wells were washed thoroughly and the enzyme substrate solution (Sigma 104 alkaline phosphatase substrates; Sigma Chemical Co.) was added. Optical density $\left(\mathrm{OD}_{405}\right)$ was read using an ELISA reader (Bio-Tek Instruments, Inc., Winooski, VT).

Animals. The animal procedures used were approved by the Animal Use Subcommittee of the Veterans Affairs Medical Center at Indianapolis, IN. Animals were handled in accordance with all applicable local and federal regulations concerning laboratory animals and were housed in our VAMC animal facility which is approved by the American Association for Accreditation of Laboratory Animal Care. ICR mice (25$30 \mathrm{~g}$ ) were obtained from Harlan Sprague Dawley, Inc. (Indianapolis, IN). Animals were housed in micro-isolators in a temperature- and humidity-controlled room with an automatic timing device that maintained lights on from 6 a.m. to 6 p.m. They were fed regular laboratory pellet food ad lib. with free access to tap water.

Culture of mouse peritoneal macrophages. Mice were anesthetized by exposure to Metofane (Pitman-Moore, Inc., Washington Crossing, $\mathrm{NJ}$ ). Blood was removed from mice by cardiac puncture. $6 \mathrm{ml}$ of icecold, sterile PBS containing heparin $(10 \mathrm{U} / \mathrm{ml})$ was then injected into the peritoneal cavity. After a few gentle strokes, the saline solution was recovered and centrifuged at $600 \mathrm{~g}$ for $10 \mathrm{~min}$ at $5^{\circ} \mathrm{C}$. The pellet was washed once in heparin-containing PBS and then resuspended in the standard DMEM medium containing $10 \%$ FCS at a concentration of $2.5 \times 10^{6}$ cells $/ \mathrm{ml}$. Routinely, $100 \mu \mathrm{g} / \mathrm{ml}$ gentamycin, $20 \mathrm{mM}$ L-glutamine, $26 \mathrm{mM} \mathrm{NaHCO}$ and $30 \mathrm{mM}$ Hepes, $\mathrm{pH} \mathrm{7.4,} \mathrm{were} \mathrm{added} \mathrm{to}$ the DMEM medium. Cells from 10-12 animals were pooled for each experiment. $2 \mathrm{ml}$ of macrophage suspension $\left(5 \times 10^{6}\right.$ cells total) were plated onto a 35-mm plastic Petri dish (Costar Corp., Cambridge, MA). After incubation for $2 \mathrm{~h}$ at $37^{\circ} \mathrm{C}$ in an incubator that had been equilibrated with $95 \%$ air $+5 \% \mathrm{CO}_{2}$, unattached cells were washed off. Fresh DMEM medium containing $20 \%$ FCS $(2 \mathrm{ml})$ was replenished to the cell monolayer in each dish. LDLs ( $50 \mu \mathrm{g}$ protein $/ \mathrm{ml})$ were also added at this time to the test dishes. The dishes were then returned to the incubator and incubated for $24 \mathrm{~h}$. The culture medium was aspirated. Serum-free DMEM medium ( $2 \mathrm{ml}$ ) was added to each dish and incubation was continued at $37^{\circ} \mathrm{C}$ for an additional $24 \mathrm{~h}$. At the end of incubation, the culture medium was collected and centrifuged to remove debris, then stored at $4^{\circ} \mathrm{C}$ until the assay of apo E. Medium apo E concentrations as measured by the ELISA method were found to be stable for at least 1 mo (data not shown). Cell monolayers were washed twice with PBS and Petri dishes were kept frozen at $-20^{\circ} \mathrm{C}$ for at least $2 \mathrm{~d}$ to facilitate cell collection. Cells were scraped off the plastic surface in $\mathrm{H}_{2} \mathrm{O}$ using a rubber policeman. Cell suspensions were sonicated. A small aliquot was used for protein concentration determination. The remaining cell suspension was extracted with methanol/chloroform (2:1) according to the method of Folch et al. for lipids (28). Lipid extracts were dried under a stream of $\mathrm{N}_{2}$ then redissolved in $50 \mathrm{mM}$ phosphate buffer containing $3 \mathrm{mM}$ sodium cholate and $0.025 \%$ Triton X-100 for the measurement of total cholesterol concentrations.

As a positive control, Ac-LDL was used in these experiments. AcLDL was prepared by repeated addition of acetic anhydride to LDL (29). Dose response for Ac-LDL has been performed previously and

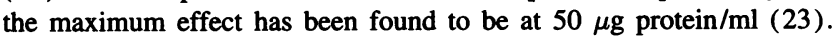
Therefore this dose of Ac-LDL was used in this work to compare the effects of Ac-LDL and LDL particles of alcoholic patients and control subjects on macrophage responses.

Quantification of apo E. Apo E in the culture medium was quantitated by a previously described ELISA method using rabbit antibody raised against rat serum apo $\mathrm{E}(30)$. The antibody also reacts specifically with mouse serum apo $\mathrm{E}$ and not with other mouse serum proteins.

Other analytical methods. Vitamin E concentration in LDL was determined by a micro-fluorometric method as described by Hansen and Warwick (31). Total cholesterol was determined by an enzymatic 
Table I. Chemical Compositions of Human LDLs

\begin{tabular}{lcccc}
\hline & Protein & Cholesterol & Triglycerides & Phospholipids \\
\hline & $\begin{array}{c}m g / m l \\
\text { plasma }\end{array}$ & & $\begin{array}{c}m g \text { lipid } \\
m g \text { protein }\end{array}$ & \\
& & & & \\
$\begin{array}{c}\text { Controls } \\
(n=48)\end{array}$ & $0.66 \pm 0.14$ & $1.33 \pm 0.24$ & $0.40 \pm 0.02$ & $0.81 \pm 0.10$ \\
$\begin{array}{c}\text { Alcoholic } \\
\text { patients } \\
(n=54)\end{array}$ & $0.60 \pm 0.21$ & $1.08 \pm 0.24^{*}$ & $0.57 \pm 0.12^{\ddagger}$ & $0.76 \pm 0.20$ \\
\hline
\end{tabular}

Data represent mean values \pm SD. Parentheses indicate number of subjects in each group. ${ }^{*} P<0.001,{ }^{\ddagger} P<0.01$, patients versus controls.

colorimetric method (32). Triglycerides and phospholipids were assayed using kits purchased from Sigma Chemical Co. and Kamiya Biomedical Co. (Thousand Oaks, CA), respectively. LDL protein concentration was determined by the BCA method (Bio-Rad Laboratories) using BSA as the standard. Lipid peroxides were quantitated by colorimetric method using an assay kit purchased from Kamiya Biomedical Co.

Statistical analysis. Data are presented as mean values \pm SD. Statistical significance between groups was determined by ANOVA. Correlation between parameters was analyzed by linear regression.

\section{Results}

Chemical compositions of LDLs from alcoholic patients and control subjects. LDL samples were measured for protein and lipid concentrations. When determined by the BCA method, protein concentrations of LDL from alcoholic patients appeared to be slightly lower than LDLs of nondrinking controls, but the differences were not statistically significant (Table I). When expressed as milligrams of lipid per milligram of protein, LDL particles from alcoholic patients contained less cholesterol ( $P$ $<0.0001)$ and more triglycerides $(P<0.01)$ than LDL particles from controls, whereas phospholipid contents were not significantly changed (Table I).

Agarose gel electrophoresis. LDL samples (5 $\mu \mathrm{g}$ each)

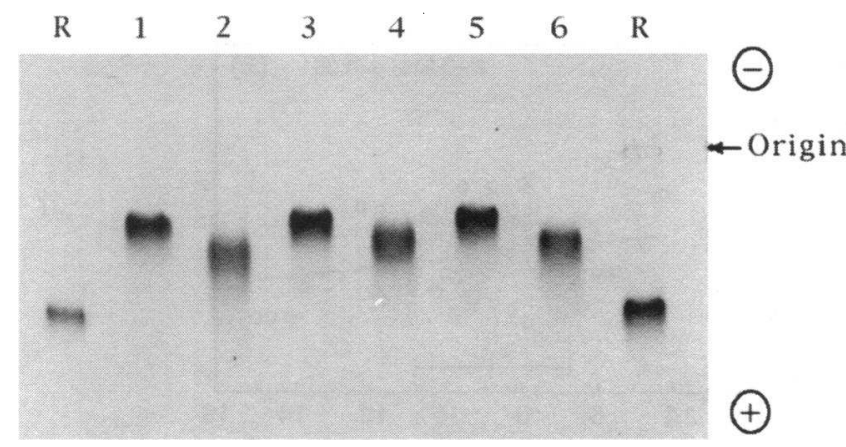

Figure 1. Electromobility of human LDL. Agarose gel electrophoresis was performed using Ciba Corning Electrophoresis System ${ }^{\mathrm{TM}}$. Each lane contained $5 \mu \mathrm{g}$ of protein. The running time was $90 \mathrm{~min}$ under constant voltage $(90 \mathrm{~V})$ at $R T$. When finished, the gel was stained with Coomassie blue to reveal protein bands. Lanes 1,3 , and 5 were LDLs from three nondrinking control subjects. Lanes 2,4 , and 6 were LDLs from three alcoholic patients. Two outside lanes $(R)$ contained $\mathrm{KLH}$, which served as the reference protein.
Table II. Electromobility and Vitamin E Content in Human LDL

\begin{tabular}{cccc}
\hline & Relative mobility & $\begin{array}{c}\text { LDL } \\
\text { vitamin E }\end{array}$ & $\begin{array}{c}\text { Plasma } \\
\text { vitamin E }\end{array}$ \\
\hline & & $\mu g / m g$ protein & $\mu g / m l$ \\
$\begin{array}{c}\text { Controls }(n=92) \\
\text { Alcoholic patients } \\
\text { Upon admission } \\
\quad(n=75)\end{array}$ & $0.396 \pm 0.046$ & $8.63 \pm 2.04$ & $16.65 \pm 4.86$ \\
$\begin{array}{c}1 \text { wk abstinence } \\
(n=29)\end{array}$ & $0.463 \pm 0.066^{*}$ & $6.99 \pm 2.09^{*}$ & $13.38 \pm 4.12^{*}$ \\
$\begin{array}{c}2 \text { wk abstinence } \\
(n=13)\end{array}$ & $0.410 \pm 0.061^{8}$ & $7.46 \pm 1.56^{\ddagger}$ & $14.47 \pm 4.36$ \\
\hline
\end{tabular}

Relative mobility $\left(R_{\mathrm{f}}\right)$ of LDL was calculated by arbitrarily setting the $R_{\mathrm{f}}$ of $\mathrm{KLH}$ as 1.0 . KLH was included in each gel and run parallelly with LDL samples. Data represent mean values \pm SD. Parentheses indicate number of subjects in each group. ${ }^{*} P<0.001$ vs controls; ${ }^{\ddagger} P$ $<0.01$ vs controls; $P<0.05$ vs upon admission.

were loaded onto agarose gel and subjected to electrophoresis. The gel was stained with Coomassie blue to locate protein bands. A representative of such a gel is shown in Fig. 1. LDL samples from three each of alcoholic patients (lanes 2, 4, and 6) and nondrinking controls (lanes 1,3 , and 5) were run in parallel with KLH ( $R$ or reference on two outer lanes) which served as the reference. It can be seen that LDLs of alcoholic patients were more negatively charged and migrated faster toward the cathode. Relative mobility $\left(R_{\mathrm{f}}\right)$ of LDL against the reference protein, i.e., $\mathrm{KLH}\left(R_{\mathrm{f}}=1.0\right)$, was calculated. Table II showed that mean $R_{\mathrm{f}}$ of LDLs from alcoholic patients $(0.463 \pm 0.066$, mean value $\pm \mathrm{SD}, n=75)$ was significantly higher than the mean $R_{\mathrm{f}}$ of LDLs from nondrinking controls $(0.396 \pm 0.046, n=92)$. The relative mobility of LDL decreased with time after abstinence from alcohol (Fig. 2) and was no longer different from normal $R_{\mathrm{f}}$ of control samples after $2 \mathrm{wk}$ (Table II).

Reactivities between $L D L$ samples and anti-KLH-AA IgG or anti-KLH-HNE IgG. ELISA method was used to test whether human LDL possessed oxidatively modified and/or

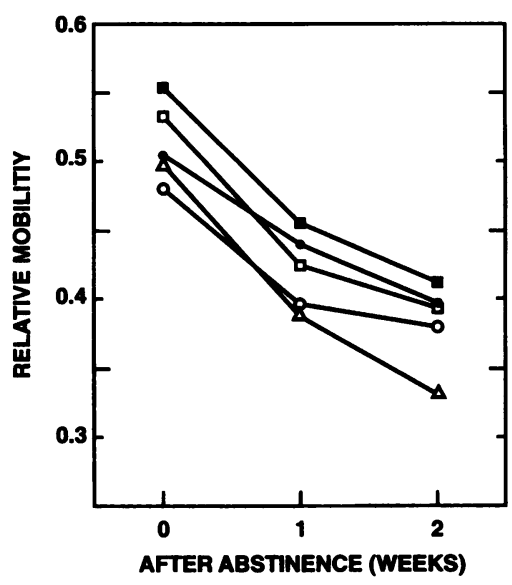

Figure 2. Effect of alcohol abstinence on the electromobility of LDL. Electrophoresis was performed as in Fig. 1. Relative mobility $\left(\boldsymbol{R}_{\mathrm{f}}\right)$ of LDL was calculated by arbitrarily setting the $R_{\mathrm{f}}$ of $\mathrm{KLH}$ as 1.0. KLH was included in each gel and run in parallel with LDL samples. LDL samples were obtained from alcoholic patients upon admission to the hospital (week 0 ) and then again at 1 and 2 wk after abstinence from alcohol while they remained in the hospital. 


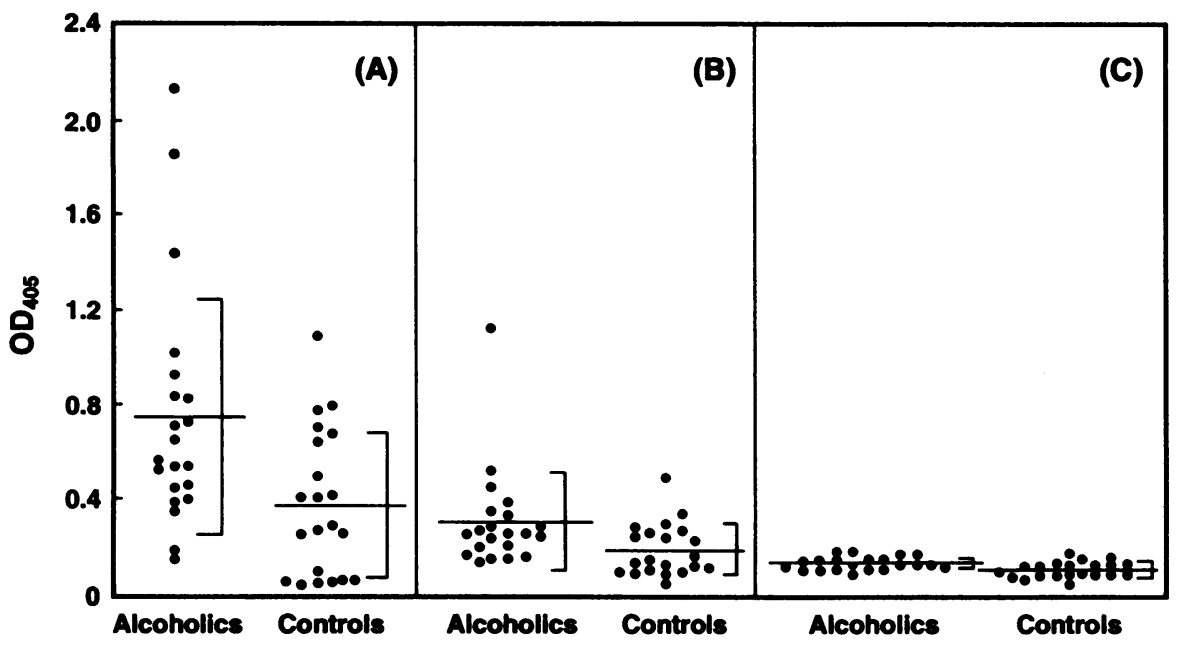

Figure 3. ELISA of human LDL. ELISA was performed by coating 96-well ELISA plates with human LDL samples $(1 \mu \mathrm{g} / 100 \mu \mathrm{l})$ as described in Methods. The first antibody used was $(A)$ rabbit anti-hemocyanin-HNE conjugate IgG; $(B)$ rabbit anti-hemocyanin-acetaldehyde adduct IgG; or $(C)$ unimmunized rabbit IgG. Horizontal lines indicate the mean value of each group $(n=21)$. Brackets indicate \pm one standard deviation. acetaldehyde-modified epitopes. When anti-KLH-HNE IgG was tested, LDLs from alcoholic patients and the nondrinking group showed $\mathrm{OD}_{405}$ of $0.741 \pm 0.510$ and $0.375 \pm 0.309(n=21$, $P<0.01$ ), respectively. When KLH-AA IgG was tested, LDLs from alcoholic patients and the nondrinking group showed $\mathrm{OD}_{405}$ of $0.312 \pm 0.216$ and $0.194 \pm 0.108(n=21, P<0.05)$, respectively. Unimmunized rabbit IgG reacted very weakly with human LDL, i.e., $0.135 \pm 0.029$ for alcoholic patients and $0.106 \pm 0.033$ for nondrinking control subjects, respectively (Fig. $3 C$ ). However, the reactivities with both anti-KLHHNE and anti-KLH-AA IgGs were somewhat scattered and exhibited a substantial degree of overlapping between patients and controls (Fig. 3, $A$ and $B$ ).

Lipid peroxides in $L D L$. Lipid peroxides in LDL samples were quantitated against the reference standard provided with the assay kit purchased from Kamiya Biomedical Co. Results are presented in Fig. 4. Except for a few alcoholic patients, LDLs of alcohol drinkers did not exhibit markedly higher lipid peroxides than LDLs of nondrinking subjects $(P>0.05)$. In

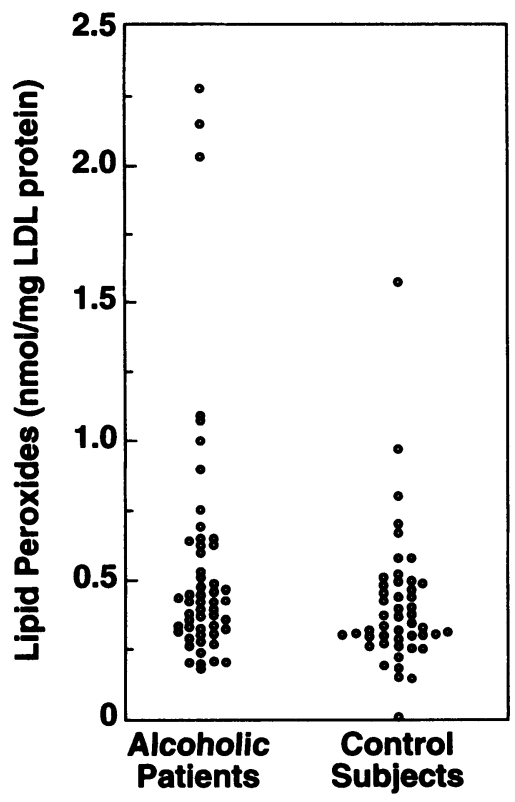

Figure 4. Lipid peroxides in human LDL. Lipid peroxides were measured by a colorimetric method using a commercial kit as described in Methods. fact, one control subject actually showed a higher level of LDL lipid peroxides than the general population of alcoholic patients.

Plasma and $L D L$ vitamin E concentrations. Vitamin E contents in plasma and LDL were measured. A good correlation between plasma and $\mathrm{LDL}$ vitamin $\mathrm{E}$ levels $(\mathrm{R}=0.757, P$ $<0.0001$ ) was demonstrated (not shown). It was found that plasma as well as LDL from alcoholic patients contained less vitamin $\mathrm{E}(13.38 \pm 4.12 \mu \mathrm{g} / \mathrm{ml}$ in plasma and $6.99 \pm 2.09 \mu \mathrm{g} /$ mg protein in LDL, $n=75$ ) than those from normal controls $(16.65 \pm 4.86 \mu \mathrm{g} / \mathrm{ml}$ in plasma and $8.63 \pm 2.04 \mu \mathrm{g} / \mathrm{mg}$ protein in LDL, $n=92$ ) (Table II and Fig. 5). Although relative mobilit-

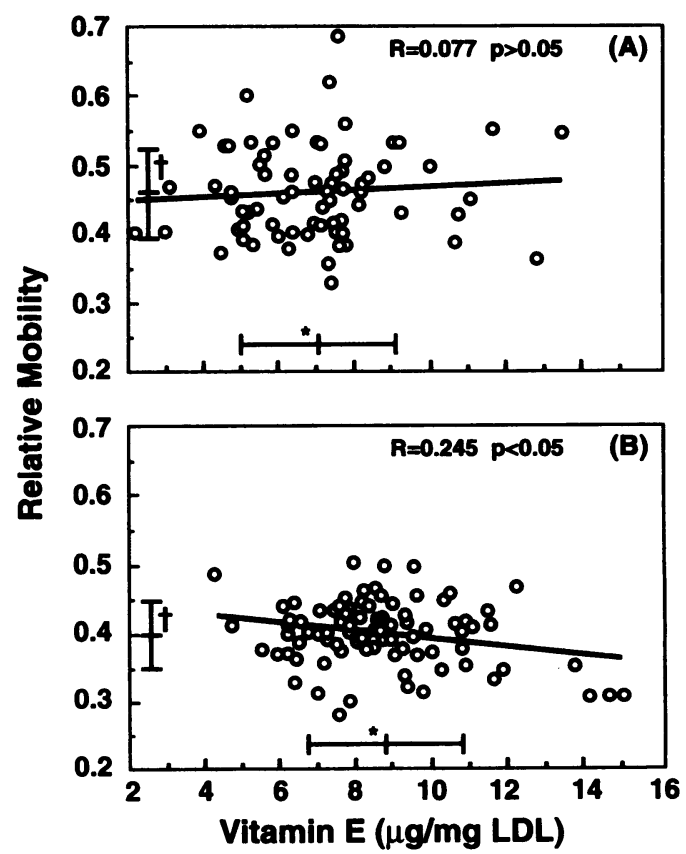

Figure 5. Correlation between electromobility and vitamin E content of LDL. Data on electromobilities and LDL vitamin E contents were from Table II. Correlation was determined by linear regression. ( $A$ ) Alcoholic patients upon admission $(n=75) ;(B)$ nondrinking control subjects $(n$ $=92) .{ }^{*}$ indicates mean value \pm SD for vitamin $\mathrm{E}$ contents in LDL $(P$ $<0.001$, alcoholics versus controls); ${ }^{\dagger}$ indicates mean value \pm SD for relative mobilities of LDLs $(P<0.001$, alcoholics versus controls $)$. 
Table III. LDL Effects on apo E Secretion and Macrophage Cellular Cholesterol Contents

\begin{tabular}{lcc}
\hline \multicolumn{1}{c}{ Source of LDL } & apo E secretion & Cellular cholesterol \\
\hline & $\mu g / m g$ protein per $24 h$ & $m g / m g$ protein \\
Controls $(n=28)$ & $0.73 \pm 0.41$ & $0.94 \pm 0.26$ \\
Alcoholic patients $(n=24)$ & $2.12 \pm 0.82 *$ & $1.48 \pm 0.32 *$ \\
\hline
\end{tabular}

Murine peritoneal macrophages were obtained by lavage of abdomen cavity. Macrophages not exposed to LDL secreted apo $\mathrm{E}$ at a rate of $0.76 \pm 0.33 \mu \mathrm{g} / \mathrm{mg}$ protein per $24 \mathrm{~h}(n=9)$ and they contained $0.81 \pm 0.30$ $\mathrm{mg}$ cellular cholesterol/mg protein $(n=9)$ at the end of incubation. Data shown in the table represent mean values \pm SD. Parentheses indicate number of subjects in each group. ${ }^{*} P<0.001$ vs controls.

ies of control LDLs exhibited a weak negative correlation with their vitamin $\mathrm{E}$ contents when analyzed by linear regression ( $R$ $=0.245, P<0.05$ ) (Fig. $5 B$ ), no such correlation was found with alcoholic LDLs $(\mathrm{R}=0.077, P>0.05)$ (Fig. $5 A)$. Furthermore, vitamin E contents in LDLs of alcoholic patients did not return to control levels after 2 wk of abstinence from alcohol even though LDL electromobilities did so (Table II).

Effects of $L D L$ on apo $E$ secretion by murine macrophages and cholesterol contents in cells. Unstimulated murine peritoneal macrophages secreted apo $E$ at a rate of $0.76 \pm 0.33 \mu \mathrm{g} / \mathrm{mg}$ cell protein per $24 \mathrm{~h}(n=9)$. As expected, the rate of apo $\mathrm{E}$ secretion increased $6-7$-fold to $4.95 \pm 1.28 \mu \mathrm{g} / \mathrm{mg}$ cell protein per $24 \mathrm{~h}$ after cells were incubated with Ac-LDL. When treated with alcoholic LDL, macrophages secreted apo $\mathrm{E}$ at a rate of $2.12 \pm 0.82 \mu \mathrm{g} / \mathrm{mg}$ cell protein per $24 \mathrm{~h}$ compared with $0.73 \pm 0.41 \mu \mathrm{g} / \mathrm{mg}$ cell protein per $24 \mathrm{~h}$ when treated with LDL from nondrinkers ( $P<0.001$, Table III). Cellular cholesterol contents of untreated macrophages were found to be $0.81 \pm 0.30$ $\mathrm{mg} / \mathrm{mg}$ cell protein. Cellular cholesterol contents did not increase significantly by incubation with control human LDLs $(0.94 \pm 0.26 \mathrm{mg} / \mathrm{mg}$ protein, $n=28, P>0.05)$. On the other hand, treatment with LDLs obtained from alcoholic patients increased macrophage cholesterol contents to $1.48 \pm 0.32 \mathrm{mg} /$ $\mathrm{mg}$ protein $(n=24, P<0.001$, Table III). There was a good correlation $(\mathrm{R}=0.746, P<0.001)$ between cellular cholesterol contents and apo $\mathrm{E}$ secretion rates when murine peritoneal macrophages were treated with human LDL (Fig. 6).

Correlations between LDL parameters and patients' physical characteristics. Correlations of chemical compositions of LDL with the age of patients were analyzed by linear regression and their correlations with the gender of patients (males versus females) or serum AST levels (normal level versus elevated level at $>40 \mathrm{U} / \mathrm{dl}$ ) were analyzed by ANOVA (Table IV). Correlations of electromobility, antigen recognition, and biological activity of LDL (as measured by its ability to stimulate apo E secretion by murine macrophages) with patients' age, gender, or AST levels were also analyzed (Table V). The results of these statistical analyses showed that LDL parameters measured in this study were neither age- nor gender-dependent, nor were these parameters changed as the result of mild liver injury present in some patients as indicated by elevated serum AST activities.

\section{Discussion}

Because an elevation of serum HDL levels is thought to be protective against atherosclerosis with moderate alcohol con-

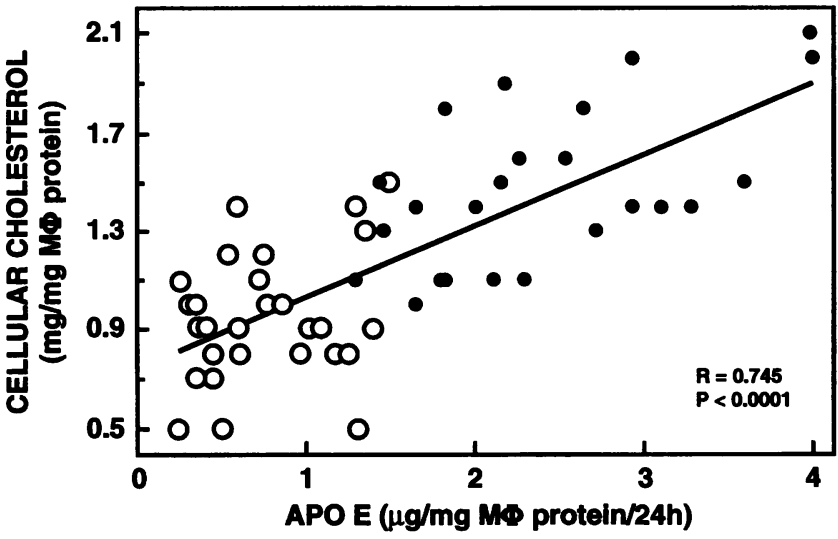

Figure 6. Correlation between cellular cholesterol contents and apo E secretion by murine peritoneal macrophages treated with human LDL. Peritoneal macrophages were obtained by lavaging the peritoneal cavity of ICR mice. Cells were cultured and treated with LDL obtained from alcoholic patients $(\bullet)$ and from nondrinking control subjects $(O)$. Correlation was determined by linear regression.

sumption (usually defined as one drink/d for women and two drinks/d for men), there has been considerable interest in alcohol effects on HDL. Comparatively, alcohol effect on LDL is inadequately studied. The report of the Cooperative Lipoprotein Phenotyping Study by Castelli et al. (3) has described a consistent observation that alcohol consumption was moderately associated with an elevation of triglycerides and moderately to strongly associated with a depression of LDL cholesterol. LDL lipid profile presented in Table I is consistent with this trend. Although our data suggested lower LDL protein contents in alcoholic patients, the decrease was not statistically significant (Table I). This result is in agreement with the finding of Huang et al. (33) who reported no significant changes in serum apo B in alcoholic patients before and after alcohol abstinence, but differs from reports by others who reported a decrease in serum apo B or LDL proteins (26, 34-36). However, it should be noted that more alcoholic patients were included in the present study than those mentioned above and therefore will influence the outcome of statistical analysis.

Our experiments showed that LDL isolated from heavy drinkers and alcoholic patients exhibited altered physical properties and, for the first time, demonstrated a change of LDL biological functions by alcohol ingestion. When subjected to

Table IV. Correlations of Chemical Compositions of $L D L$ with Patients' Age, Gender, or AST Levels

\begin{tabular}{lccccc}
\hline & \multicolumn{5}{c}{ LDL chemical compositions } \\
\cline { 2 - 6 } & Protein & Vitamin E & Cholesterol & Phospholipids & Triglycerides \\
\hline Age & 0.247 & 0.800 & 0.555 & 0.205 & 0.915 \\
Gender & 0.694 & 0.983 & 0.829 & 0.725 & 0.317 \\
AST & 0.203 & 0.707 & 0.338 & 0.548 & 0.284 \\
\hline
\end{tabular}

Correlations ( $P$ values) of LDL chemical compositions with age were analyzed by linear regression. Correlations ( $P$ values) of LDL chemical compositions with gender (males versus females) or AST (normal vs $>40 \mathrm{U} / \mathrm{dl}$ groups) were analyzed by ANOVA. 
Table V. Correlations of Electromobility, Antigen Recognition, and Biological Activity of LDL with Patients' Age, Gender, or AST Levels

\begin{tabular}{lcccc}
\hline & \multicolumn{4}{c}{ LDL characteristics } \\
\cline { 2 - 5 } & Electromobility & $\begin{array}{c}\text { Acetaldehyde } \\
\text { adduct }\end{array}$ & $\begin{array}{c}\text { Oxidatively } \\
\text { modified epitope }\end{array}$ & $\begin{array}{c}\text { Biological } \\
\text { activity* }\end{array}$ \\
\hline Age & 0.264 & 0.906 & 0.519 & 0.391 \\
Gender & 0.748 & 0.619 & 0.589 & 0.380 \\
AST & 0.348 & 0.959 & 0.755 & 0.368 \\
\hline
\end{tabular}

Correlations ( $P$ values) of LDL characteristics with age were analyzed by linear regression. Correlations ( $P$ values) of LDL characteristics with gender (males versus females) or AST (normal vs $>40 \mathrm{U} / \mathrm{dl}$ groups) were analyzed by ANOVA. * Stimulation of apo E synthesis by macrophages.

electrophoresis on agarose gel, LDL of alcoholic patients migrated faster toward the cathode than LDL from nondrinking control subjects (Fig. 1, Table II) indicating a decrease in positive charge. A remarkable change in electromobility is noticed when LDL is modified in vitro by acetylation or by incubation with heavy metal ions, e.g., $\mathrm{Cu}^{2+}$ or $\mathrm{Fe}^{2+}$ (37), but not when LDL is modified by incubation with phospholipase $C$ (23). We therefore searched for evidences of chemical modification in human LDL by ELISA methods using antibodies that will specifically recognize either protein acetaldehyde adducts (25) or oxidatively modified proteins, e.g., HNE adducts (26). The reactivities of LDL samples from alcoholic patients with both anti-KLH-AA and anti-KLH-HNE antibodies were significantly higher than LDL samples from control subjects (Fig. 3 ). However, a sizable overlap between alcohol and control groups was seen with both antibodies. These data suggest that oxidatively modified and acetaldehyde-modified epitopes exist in LDL fraction of many alcoholic patients as well as some nondrinkers. The detection of acetaldehyde-modified LDL in alcoholic patients is in agreement with Wehr et al. (21) who also reported a small increase in anti-KLH-AA IgG reactivity in alcoholic LDL. Wehr et al. used anti-KLH-AA IgG prepared by using $\mathrm{KLH}$ incubated with acetaldehyde under conditions different from ours (38). The oxidative modification in LDL detected by our anti-KLH-HNE IgG most likely involves protein moieties of LDL because only low levels of lipid peroxides were found in LDLs of most alcoholic and control samples (Fig. 4). Ox-LDL in circulation has not been reported previously although it has been detected in atherosclerotic plaque in humans and in rabbits by histoimmunological methods (20). Nevertheless, we found poor correlations between electromobilities of LDL samples and their reactivities with either antiKLH-AA or anti-KLH-HNE IgG. It should be pointed out that we have demonstrated previously that, depending on the conditions under which the immunogen (KLH-AA or KLHHNE) was prepared in vitro, antibodies raised against modified proteins may recognize only certain types of epitopes (39). Therefore, it is likely that additional epitopes (including other oxidatively modified and acetaldehyde-modified epitopes) not recognized by antibodies used in this study also exist in LDL.

Vitamin $\mathrm{E}$ is the major lipid-soluble antioxidant in plasma lipoproteins (40). This antioxidant has been found to protect LDL from lipid peroxidation in vitro and in vivo (41-43) and its levels in plasma were reported to be negatively correlated with the incidence of ischemic heart disease (44). Because our data indicated the existence of Ox-LDL, vitamin $\mathrm{E}$ contents in LDL fractions were measured. Similar to Girre et al. (45), we found plasma vitamin $\mathrm{E}$ levels to be lower in alcoholic patients (without severe liver disease) than those in nondrinkers (Table II). We further showed that vitamin E contents of LDL were proportionally lowered as in plasma by chronic alcohol drinking. The vitamin $\mathrm{E}$ levels did not return to normal within $2 \mathrm{wk}$ after cessation of alcohol (Table II). Of note, only a very low dose of vitamin E (30 IU/d) was routinely given as a vitamin supplement to detox patients at Fairbanks Hospital. Among nondrinking subjects, LDL electromobilities exhibited a weak but significant negative correlation with vitamin E contents (Fig. 5 $B$ ). This finding is consistent with that of Tribble et al. (43) who reported that oxidative susceptibility of LDL was related to its vitamin $\mathrm{E}$ contents. However, no such correlation between electromobilities and vitamin E contents in LDL of alcoholic patients was seen (Fig. $5 \mathrm{~A}$ ). Furthermore, we observed that LDL electromobilities returned to normal even though LDL vitamin $\mathrm{E}$ contents remained suppressed after 2 wk of abstinence from alcohol (Table II). Therefore, although some form of oxidative modification(s) including HNE adducts has taken place in LDL of alcoholic patients, the altered electromobility is not a direct consequence of vitamin $\mathrm{E}$ deficiency that resulted from heavy alcohol consumption. Perhaps the presence of acetaldehyde adducts (those detected by our antibody and those undetected) obscures the expected relationship between LDL electromobilies and LDL vitamin $\mathrm{E}$ contents.

Native unmodified LDL is taken up by hepatocytes and by peripheral cells via LDL (apo B,E) receptors (14). Although cholesterol is transported into cells concomitantly with LDL, the amount of cholesterol accumulated in the cells remains low because LDL receptors are downregulated by increases in cellular cholesterol contents (14). Modified LDL is known to exhibit altered biological activities. For instance, LDLs modified by acetylation or by incubation with $\mathrm{Cu}^{2+}$ or $\mathrm{Fe}^{2+}$ are taken up via scavenger receptors and by some yet uncharacterized Ox-LDL receptors (15-17). These receptors for modified LDLs are not downregulated by increases in cellular cholesterol and cells become overloaded with cholesterol (15). Resident peritoneal macrophages can synthesize a very small amount of apo $\mathrm{E}$ (46), but the synthesis of apo $E$ is greatly enhanced when macrophages take up Ac-LDL (47). Our recent study has demonstrated that LDL modified by other means such as by incubation with $\mathrm{Cu}^{2+}$ or $\mathrm{Fe}^{2+}$ or by treatment with phospholipase $\mathrm{C}$ also induces apo $\mathrm{E}$ synthesis and cholesterol accumulation in macrophages (23). To test whether the in vivo modified LDL found in alcoholic patients can stimulate apo $\mathrm{E}$ synthesis by macrophages, isolated LDL samples from these patients were incubated with murine macrophages. The results showed that LDL samples from most of the alcoholic patients induced macrophage apo E secretion (Fig. 6) by an average of threefold over control subjects (Table III). Macrophages incubated with patients' LDL samples also acquired higher cellular cholesterol contents (1.5-fold) than cells incubated with LDL samples from nondrinkers (Table III). Linear regression analysis of the data showed a good correlation between apo E secretion rates and macrophage cellular cholesterol contents after LDL treatment (Fig. 6). However, our previous study (23) has demonstrated that stimulation of apo E synthesis by LDLs modified by different biochemical processes (i.e., acetylation, oxidation, and en- 
zymatic) does not always respond in parallel to cellular cholesterol contents in rat peritoneal macrophages nor does it correspond to de novo cholesterol synthesis. Thus, until further experiments are carried out, it is uncertain whether these two events (i.e., increased apo $E$ secretion and accumulation of cholesterol in cells) responding to the treatment of alcoholic LDL samples are causally related. The effects on apo E synthesis by macrophages and electromobilities of LDL showed a tendency for a positive correlation but the correlation failed to reach statistical significance $(\mathrm{R}=0.25, P=0.06)$. This tendency is more or less expected because altered electromobilities represent a crude index for chemical changes in LDL. The effects of LDL samples on apo $\mathrm{E}$ synthesis by macrophages also correlated poorly with the degrees of reactivities toward either anti-KLH-AA or anti-KLH-HNE antibody. It is possible that our antibodies used here may not fully recognize all the epitope changes brought about by acetaldehyde adduct formation and oxidative modification in patients' LDL. Alternatively, the poor correlation may indicate that only minimum biochemical changes in LDL are needed to stimulate macrophage apo $\mathrm{E}$ secretion and that these small biochemical changes in alcoholic LDL are below the sensitivity of detection by the ELISA method. It is interesting to note that recent reports $(48,49)$ have shown that LDL minimally modified by oxidation is capable of inducing endothelial cells to secrete a high level of monocytic chemotactic activity and to produce colony-stimulating factor. Therefore it appears that a change in biological activity of modified LDL can be detected more readily than present methods available to detect physical changes in LDL. The nature and the extent of LDL modifications in alcoholic patients remain to be fully elucidated. Our findings reported here represent only an initial effort.

In summary, we report here that LDL of alcoholic patients contains less vitamin $E$, is chemically modified in vivo, and exhibits altered biological function. These changes may render LDL in alcoholics more atherogenic. Our recent study (50) has shown that HDL-apo AI levels are increased in alcoholic patients. The more atherogenic LDL in alcoholic patients we report here may overwhelm the antiatherogenic effects of increased HDL-apo AI and thus would explain at least in part the higher incidence of atherosclerosis in heavy alcohol drinkers.

\section{Acknowledgments}

The authors are indebted to Bobbi Miller and David Radtke for blood sample collection and for isolation of $\cdot$ LDL. We thank Dr. Timothy J. Kelly, Tim Boruff, and the staff at Fairbanks Hospital, Indianapolis, IN, for their dedication and cooperation.

The study was supported by National Institutes of Health grants (AA-06991 and AA-07647) and Veterans Affairs Merit Review funds.

\section{References}

1. Moore, R. D., and T. A. Pearson. 1986. Moderate alcohol consumption and coronary artery disease. A review. Medicine (Baltimore). 65:242-267.

2. Kagan, A., K. Yano, G. C. Rhoads, and D. L. McGee. 1981. Alcohol and cardiovascular disease: the Hawaiian experience. Circulation. 64:11127-11131.

3. Castelli, W. P., T. Gordon, M. C. Hjortland, A. Kagan, J. T. Doyle, C. G. Hames, S. B. Hulley, and W. J. Zukel. 1977. Alcohol and blood lipids: the cooperative lipoprotein phenotyping study. Lancet. 2:153-155.

4. Gordon, T., N. Ernst, M. Fisher, and B. M. Rifkind. 1981. Alcohol and high density lipoprotein cholesterol. Circulation. 64:11163-11167.

5. Miller, N. E., C. H. Bolton, T. M. Hayes, D. Bainton, J. W. G. Yarnell, I. A. Baker, and P. M. Sweetnam. 1988. Association of alcohol consumption with plasma high density lipoprotein cholesterol and its major subfractions. The
Caerphilly and Speedwell collaborative heart disease studies. J. Epidemiol. Community Health. 42:220-225.

6. Miller, G. J., and N. E. Miller. 1975. Plasma-high-density-lipoproteinconcentration and development of ischemic heart disease. Lancet. 1:16-19.

7. Wilson, P. W. F., R. D. Abbott, and W. P. Castelli. 1988. High density lipoprotein cholesterol and morality. The Framingham Heart Study. Circulation. 8:737-741.

8. Marmot, M. G. 1984. Alcohol and coronary heart disease. Int. J. Epidemiol. 13:160-167.

9. Criqui, M. H. 1986. Alcohol consumption, blood pressure, lipids, and cardiovascular mortality. Alcohol. Clin. Exp. Res. 10:564-569.

10. Kannel, W. B. 1988. Alcohol and cardiovascular disease. Proc. Nutr. Soc. 47:99-110.

11. Gordon, T., W. B. Kannel, and W. P. Castelli. 1981. Lipoproteins, cardiovascular disease and death. The Framingham Study. Arch. Intern. Med. 141:11281131.

12. Gordon, T., W. P. Castelli, and M. C. Hjortland. 1977. High density lipoprotein as a protective factor against coronary heart disease. The Framingham Study. Am. J. Med. 62:707-714.

13. Steinberg, D., S. Parthasarathy, T. E. Carew, J. C. Khoo, and J. L. Witztum. 1989. Beyond cholesterol: modifications of low-density lipoprotein that increase its artherogenicity. In Mechanisms of Disease. F. H. Epstein, editor. N. Engl. J. Med. 320:915-924.

14. Brown, M. S., and J. L. Goldstein. 1983. Lipoprotein receptors in the liver. J. Clin. Invest. 72:743-747.

15. Brown, M. S., S. K. Basu, J. R. Falck, Y. K. Yo, and J. L. Goldstein. 1980. The scavenger cell pathway for lipoprotein degradation: specificity in the binding site that mediates the uptake of negatively-charged LDL by macrophages. J. Supramol. Struct. 12:67-81.

16. Parthasarathy, S., L. G. Fong, D. Otero, and D. Steinberg. 1987. Recognition of solubilized apoproteins from delipidated, oxidized low density lipoprotein (LDL) by the acetyl-LDL receptor. Proc. Natl. Acad. Sci. USA. 84:537-540.

17. Arai, H., T. Kita, M. Yokode, S. Narumiya, and C. Kawai. 1989. Multiple receptors for modified low density lipoproteins in mouse peritoneal macrophages: different uptake mechanisms for acetylated and oxidized low density lipoproteins. Biochem. Biophys. Res. Commun. 159:1375-1382.

18. Sparrow, C. P., S. Parthasarathy, and D. Steinberg. 1989. A macrophage receptor that recognizes oxidized low density lipoprotein but not acetylated low density lipoprotein. J. Biol. Chem. 264:2599-2604.

19. Matsumoto, A., M. Naito, H. Itakura, S. Ikemoto, H. Asaoka, I. Hayakawa, H. Kanamori, H. Aburatani, T. Fumimaro, H. Suzuki, et al. 1990. Human macrophage scavenger receptors: primary structure expression, and localization in atherosclerotic lesions. Proc. Natl. Acad. Sci. USA. 87:9133-9137.

20. Yla-Herttuala, S., W. Palinski, M. E. Rosenfeld, S. Parthasarathy, T. E. Carew, J. L. Witztum, and D. Steinberg. 1989. Evidence for the presence of oxidatively modified low density lipoprotein in atherosclerotic lesions of rabbit and man. J. Clin. Invest. 84:1086-1095.

21. Wehr, H., M. Rodo, C. S. Lieber, and E. Baraona. 1993. Acetaldehyde adducts and autoantibodies against VLDL and LDL in alcoholics. J. Lipid Res. 34:1237-1244.

22. Basu, S. K., J. L. Goldstein, R. W. Anderson, and M. S. Brown. 1976. Degradation of cationized low density lipoprotein and regulation of cholesterol metabolism in homozygous familial hypercholesterolemia fibroblasts. Proc. Natl. Acad. Sci. USA. 73:3178-3182.

23. Zhang, M. Y., and R. C. Lin. 1994. Oxidative-modified and acetylated low density lipoproteins differ in their effects on cholesterol synthesis and stimulate synthesis of apolipoprotein $\mathrm{E}$ in rat peritoneal macrophages by different mechanisms. Metab. Clin. Exp. 43:1523-1530.

24. Havel, R. J., H. A. Eder, and J. H. Bragdon. 1955. The distribution and chemical composition of ultracentrifugally separated lipoproteins in human serum. J. Clin. Invest. 34:1345-1353.

25. Lin, R. C., R. S. Smith, and L. Lumeng. 1988. Detection of a proteinacetaldehyde adduct in the liver of rats fed alcohol chronically. J. Clin. Invest. 81:615-619.

26. Palinski, W., S. Yla-Herttuala, M. E. Rosenfeld, S. W. Butler, S. A. Socher, S. Parthasarathy, L. K. Curtiss, and J. L. Witztum. 1990. Antisera and monoclonal antibodies specific for epitopes generated during oxidative modification of low density lipoprotein. Arteriosclerosis. 10:325-335.

27. Lin, R. C., S. Shahidi, T. J. Kelly, C. Lumeng, and L. Lumeng. 1993. Measurement of hemoglobin-acetaldehyde adducts in alcoholic patients. Alcohol. Clin. Exp. Res. 17:669-674.

28. Folch, J., M. Lees, and G. H. Sloane Stanley. 1957. A simple method for the isolation and purification of total lipids from animal tissues. J. Biol. Chem. 226:497-509.

29. Goldstein, J. L., Y. K. Ho, S. K. Basu, and M. S. Brown. 1979. Binding site on macrophages that mediates uptake and degradation of acetylated low density lipoprotein producing massive cholesterol deposition. Proc. Natl. Acad. Sci. USA. 76:333-337.

30. Lin, R. C. 1986. Quantification of apolipoproteins in rat serum and in 
cultured rat hepatocytes by enzyme-linked immunosorbent assay. Anal. Biochem. $154: 316-326$.

31. Hansen, L. G., and W. J. Warwick. 1966. A fluorometric micro method for serum tocopherol. Am. J. Clin. Pathol. 46:133-138.

32. Lin, R. C., L. Lumeng, and V. L. Phelps. 1989. Serum HDL particles of alcohol-fed rats are deficient in apolipoprotein E. Hepatology (NY). 9:307-313.

33. Huang, C. M., R. J. Elin, M. Ruddel, J. Schmitz, and M. Linnoila. 1992. The effect of alcohol withdrawal on serum concentrations of $\mathrm{Lp}(\mathrm{a})$, apolipoproteins A-1 and B, and lipids. Alcohol. Clin. Exp. Res. 16:895-898.

34. Naruszewicz, M., E. W. A. Mirkiewicz, and H. Wehr. 1990. Abnormal low density lipoproteins composition in some chronic alcoholics: a possible mechanism. Alcohol Alcohol. 25:533-538.

35. Kervinen, K., M. J. Savolaninen, and Y. A. Kesaniemi. 1991. Multiple changes in apoprotein B containing lipoproteins after ethanol withdrawal in alcoholic men. Ann. Med. 23:407-413.

36. Barboriak, J. J., P. Alaupovic, and P. Cushman. 1981. Abstinence-induced changes in plasma apolipoprotein levels of alcoholics. Drug Alcohol Depend. 8:337-343.

37. Kalyanaraman, B., J. Joseph, and S. Parthasarathy. 1993. Site-specific trapping of reactive species in low-density lipoprotein oxidation: biological implications. Biochim. Biophys. Acta. 1168:220-227.

38. Behrens, U. J., M. Hoerner, J. M. Lasker, and C. S. Lieber. 1988. Formation of acetaldehyde adducts with ethanol-inducible P450IIE1 in vivo. Biochem. Biophys. Res. Commun. 154:584-590.

39. Lin, R. C., S. Shahidi, and L. Lumeng. 1993. Production of antibodies that recognize the heterogeneity of immunoreactive sites in human hemoglobin chemically modified by acetaldehyde. Alcohol. Clin. Exp. Res. 14:882-886.

40. Kayden, H. J., and M. G. Traber. 1993. Absorption, lipoprotein transport, and regulation of plasma concentrations of vitamin $\mathrm{E}$ in humans. J. Lipid Res. 34:343-358.

41. Esterbauer, H., M. Dieber-Rotheneder, G. Striegl, and G. Waey. 1991. Role of vitamin $\mathrm{E}$ in preventing the oxidation of low density lipoprotein. Am. J. Clin. Nutr. 53:314S-321S.
42. Frei, B., and J. M. Gaziano. 1993. Content of antioxidants, preformed lipid hydroperoxides, and cholesterol and predictors of the susceptibility of human LDL to metal ion-dependent and -independent oxidation. J. Lipid Res. 34:21352145.

43. Tribble, D. L., J. J. M. Van Den Berg, P. A. Motchnik, B. N. Ames, D. M. Lewis, A. Chait, and R. M. Krauss. 1994. Oxidative susceptibility of low density lipoprotein subfractions is related to their ubiquinol-10 and tocopherol content. Proc. Natl. Acad. Sci. USA. 91:1183-1187.

44. Gey, K. F., P. Puska, P. Jordan, and U. K. Moser. 1991. Inverse correlation between plasma vitamin $\mathrm{E}$ and mortality from ischemic heart disease in crosscultural epidemiology. Am. J. Clin. Nutr. 53:326S-334S.

45. Girre, C., E. Hispard, P. Therond, S. Guedj, R. Bourdon, and S. Dally. 1990. Effect of abstinence from alcohol on the depression of glutathione peroxidase activity and selenium and vitamin $\mathbf{E}$ levels in chronic alcoholic patients. Alcohol. Clin. Exp. Res. 14:909-912.

46. Werb, F., and J. R. Chin. 1983. Apoprotein E is synthesized and secreted by resident and thioglycollate-elicited macrophages but not by pyran copolymer or bacillus calmette-guerin-activated macrophages. J. Exp. Med. 158:1272-1293.

47. Brown, M. S, and J. L. Goldstein. 1983. Lipoprotein metabolism in macrophage: implications for cholesterol deposition in atherosclerosis. Annu. Rev. Biochem. 52:223-261.

48. Berliner, J. A., M. C. Territo, A. Sevanian, S. Ramin, J. A. Kim, B. Bamshad, M. Esterson, and A. M. Fogelman. 1990. Minimally modified low density lipoprotein stimulates monocyte endothelial interactions. J. Clin. Invest. 85:1260-1266.

49. Rajavashisth, T. B., A. Andalibi, M. C. Territo, J. A. Berliner, M. Navab, A. M. Fogelman, and A. J. Lusis. 1990. Induction of endothelial cell expression of granulocyte and macrophage colony-stimulating factors by modified low-density lipoproteins. Nature (Lond.). 344:254-257.

50. Lin, R. C., B. A. Miller, and T. J. Kelly. 1995. Concentrations of apolipoprotein AI, AII and E in plasma and in lipoprotein fractions of alcoholic patients: gender differences in the effects of alcohol. Hepatology. In press. 